\title{
Assessing Redox Properties of Natural Organic Matters with regard to Electron Exchange Capacity and Redox-Active Functional Groups
}

\author{
Zhiyuan Xu $\mathbb{D}^{1},{ }^{1}$ Zhen Yang, ${ }^{2}$ Hongping Wang $\mathbb{D}^{1},{ }^{1}$ and Jie Jiang $\mathbb{D}^{1}$ \\ ${ }^{1}$ Beijing Key Laboratory for Source Control Technology of Water Pollution, College of Environmental Science and Engineering, \\ Beijing Forestry University, Beijing 100083, China \\ ${ }^{2}$ Geomicrobiology, Center for Applied Geoscience, University of Tuebingen, Tuebingen 72076, Germany
}

Correspondence should be addressed to Jie Jiang; jiangjie@bjfu.edu.cn

Received 27 December 2019; Revised 16 February 2020; Accepted 11 March 2020; Published 14 April 2020

Guest Editor: Chenglian Feng

Copyright (C) 2020 Zhiyuan Xu et al. This is an open access article distributed under the Creative Commons Attribution License, which permits unrestricted use, distribution, and reproduction in any medium, provided the original work is properly cited.

Redox processes in groundwater play an important role in bioavailability, toxicity, and mobility of redox-active elements and contaminants. A recent study has demonstrated that low-molecular-weight fraction (LMWF) of humic substances with great number of redox-active functional groups (RAFGs) exhibits great reducing capacity. However, whether LMWF of natural organic matter (NOM) exhibits high redox capacity still remains unclear. Therefore, this study extracted Pahokee peat NOM (PPNOM) and Leonardite NOM (LNOM) from soils, and then LMWFs in these NOMs were collected using a dialysis method. Electron exchange capacities (EEC) and RAFGs of LMWF NOMs at different $E_{\mathrm{h}}$ were analyzed using a novel electrochemical method and a three-dimensional excitation emission fluorescence (3DEEM) spectroscopy. We found that the reducing capacity in LMWF PPNOM was approximately 5-6 times higher than the bulk NOM, while only 7.8\% LMWF PPNOM was accounted for in the bulk NOM. An increasing in EEC (EAC+EDC, where EAC is the electron accepting capacity and EDC is the electron donating capacity) of LMWF PPNOM and LNOM with $E_{\mathrm{h}}$ reduced from $-0.49 \mathrm{~V}$ to $-0.69 \mathrm{~V}$. Additionally, an obvious increase in fluorescent intensities of quinone-like fluorophores before and after being reduced LMWF LNOM is responsible for high EAC of LMWF LNOM. These findings provide a better understanding of relationship between RAFGs $E_{\mathrm{h}}$ in LMWF of NOM, further helping in predicting and protection of groundwater environment and fate of transformation and transport for redox-active contaminants in groundwater.

\section{Introduction}

Natural organic matters, as the most important redox-active compounds, participate in transformation and transport of redox-active elements and contaminants in biogeochemical processes in groundwater systems [1-4]. In addition, the chemical speciation, bioavailability, toxicity, and mobility of these redox-active compounds coupled with degradation of natural organic matter (NOM) $[5,6]$ are dependent on redox conditions. NOM can mediate electron transfer during the biogeochemical processes including microbial reduction of $\mathrm{Fe}(\mathrm{III})$ hydroxides $[2,7,8]$ processed with immobilization of arsenic and phosphate [9]. The capacities of electron charging and recharging processes of $\mathrm{NOM}$ is related to redox conditions $\left(E_{\mathrm{h}}\right)[10]$ and redox-active functional groups (RAFGs). NOM varies greatly in chemical and structural properties and thus change reactivity in the soil environment [11-13] that evolves from oxygen reducing to methanogenic (low reducing condition). RAFGs of NOM, including coexistence of electron donor moieties (e.g., phenolic and possibly substituted aromatic carboxylic acid groups) [14-16] and electron acceptor moieties (e.g., carbonyl-containing groups) [17-19], are responsible for cycling of electron charge-recharge within redox reactions [3, 20-25].

Quinone/hydroquinone moieties are generally considered to be the main redox-active functional groups of natural organic matter [26]. In general, NOM can be chemical and 
microbial reduced, and reduced NOM facilitates electron transfer-stimulating microbial $\mathrm{Fe}[\mathrm{III}]$ minerals. The extent and rate of stimulated microbial Fe[III] reduction is relating to redox property of NOM. Reducing capacities of NOM include electron accepting capacity (EAC) and electron donating capacity (EDC). NOM can be chemically reduced by $\mathrm{H}_{2}$ in the presence of a Pd catalyst resulting in the different reducing capacities before and after being reduced. [25, 26]. Alternatively, the electrochemical reduction is a more efficient method compared to the chemical reduction $[10,27]$. Previous electrochemical studies have revealed redox properties of NOM in varied redox potential range of $-0.9 \mathrm{~V}-+1.0 \mathrm{~V}$, which significantly affects transformation and electron transfer rates of pollutants in soil environments [28].

Many redox-active contaminants (such as arsenic, phosphate, and sulfate) normally are stocked in these soil nanoscale pores that have limited access to microbes $[3,21,23,29,30]$, leading to hard transformation and transport, thus substantially arising a risk in soil groundwater health. It has been demonstrated that low-molecular-weight fractions (LMWFs) released from bulk humic substances (HSs) can exhibit great reducing capacity. The high reducing capacity of LMWF HS is attributed to LMWF HS, possessing a high amount of quinone-like fluorophores detected by threedimensional excitation-emission matrix (3DEEM) fluorescence spectroscopy [26]. These LMWF HSs flowing into and/ or out of the soil micropores $(<2 \mathrm{~nm})$ are able to significantly impact fates of transport and transformation of redox-active contaminants [26]. However, still opening questions including whether LMWF exists in natural organic matter (NOM), to which extent of electron transfer capacities of LMWF in NOMs at varied $E_{\mathrm{h}}$ in soil environment, and relationship of its RAFGs and $E_{\mathrm{h}}$ has paid a little attention.

Therefore, the aims of this study were (i) to collect different LMWFs (3500 LMWF and 14000 LMWF) and retentate from bulk NOM by means of a dialysis method with dialysis bags of molecules cutoff of 3.5 and $14 \mathrm{KDa}$; (ii) to determine electron exchange capacities (EECs) including electron accepting/donating capacity (EAC/EDC) at a varied $E_{\mathrm{h}}$ range of $0--0.69 \mathrm{~V}$ of LMWF, retentate, and bulk Pahokee peat and Leonardite natural organic matters (PPNOM and LNOM) using chemical (by $\mathrm{H}_{2}$ and $\mathrm{Pt} / \mathrm{Al}$ ) and electrochemical analysis; and (iii) finally to detect redox-active functional fluorophores by 3DEEM for different molecular weight fractions of NOM at native and varied reduced $E_{\mathrm{h}}$ state $(-0.49--0.69 \mathrm{~V})$. We expected to develop a potential relationship between EEC and its RAFGs for different LMWF NOMs according to gradient $E_{\mathrm{h}}$ range of $-0.49--0.69 \mathrm{~V}$ to better understand and predict fates of electron transfer process of LMWF NOM during the biogeochemistry process in soil and groundwater environments.

\section{Materials and Methods}

2.1. Sample Preparation and Dialysis Experiments. Pahokee peat soil and Leonardite soil were purchased from the International Humic Substances Society (IHSS). PPNOM and LNOM were extracted from Pahokee peat soil and Leonardite soil samples $(3.85 \mathrm{~g} / \mathrm{L})$ that dissolved in a phosphate buffer solution (PP buffer; $50 \mathrm{mM}, \mathrm{pH}$ 7) to achieve final approximately total organic carbon (TOC) contents of $250 \mathrm{mg} \mathrm{C/L}$. The NOM samples in sealed glass bottles with aluminum foil wrap were in continuous stirring for 5 days $(200 \mathrm{rpm})$ to ensure fully release.

Dialysis bags were purchased from MWCO Regenerate (VISKASE, US). Before dialysis experiments, the chosen dialysis bags, MD34-3500 (pore size $1.25 \mathrm{~nm}$ ) and MD3414000 (pore size $2.5 \mathrm{~nm}$ ), were prior soaked in deionized water for 24 hours. The dialysis bag containing $50 \mathrm{~mL}$ bulk sample was submerged in beaker with $200 \mathrm{~mL}$ PP buffer, and the whole device was wrapped in aluminum foil to prevent photochemical reaction. At the same time, the stirring rate was set to $200 \mathrm{rpm}$ to simulate flowing rate of water in underground environment. The TOC $(\mathrm{mg} \mathrm{C} / \mathrm{L})$ was determined by TOC-V scan analyzer (SHIMADZU).

\subsection{Electrochemical Analysis with Direct Electrochemical} Reduction (DER). All electrochemical experiments were conducted in an anoxic glove box $\left(100 \% \mathrm{~N}_{2}\right.$ atmosphere at $25 \pm 1^{\circ} \mathrm{C}$ ). An electrolysis cell consists of (i) a platinum disk working electrode (CHI102), (ii) an $\mathrm{Ag} / \mathrm{AgCl}$ reference electrode (CHI111), and (iii) a Pt wire counter electrode (CHI115, all from $\mathrm{CH}$ Instruments, Inc. US). The current response I was determined by $\mathrm{CH}$ Instruments 660E (Austin, TX). All samples were vacuumed for 3 mins, followed by purging with $\mathrm{N}_{2}$ for 3 mins three times before electrochemical experiment. $0.1 \mathrm{M} \mathrm{KCl}$ was used as supporting electrolyte during electrochemical experiment. Each of $4 \mathrm{~mL}$ sample in an electrolysis cell was directly electrochemical reduced at an electrode potential of $-0.49 \mathrm{~V},-0.59 \mathrm{~V}$, and $-0.69 \mathrm{~V}$, respectively.

\subsection{Electrochemical Analysis with Direct Electrochemical} Oxidation (DEO). All setups of DEO experiments completely followed DER experiments instead of the $+0.61 \mathrm{~V}$ applied potential in DEO.

The number of transferred electrons $\mathrm{Q}_{\mathrm{DER}}$ and $\mathrm{Q}_{\mathrm{DEO}}$ $(\mu \mathrm{mol})$ was calculated by an integration of the reductive and oxidative currents I over the time $t(s)$, respectively [10]. Considering the differences in different molecular weight fractions based on TOC contents, EEC (mmol e-/g C) of each sample was normalized to TOC:

$$
\begin{aligned}
Q_{D E O} & =\int \frac{I_{O X}}{F} d t, \\
Q_{D E R} & =\int \frac{I_{R E}}{F} d t, \\
\mathrm{EAC} & =\frac{Q_{D E R}}{T O C \times V}, \\
\mathrm{EDC} & =\frac{Q_{D E O}}{T O C \times V}, \\
E E C & =|E A C|+|E D C|,
\end{aligned}
$$

where $\mathrm{F}$ is a Faraday constant $(96485(\mathrm{C} / \mathrm{mol}))$ and $\mathrm{V}(\mathrm{mL})$ is a volume of reaction samples. The EDC and I-t curve in DEO 
TABLE 1: TOC contents (mg C/L) of different molecular weight fractions (including LMWF, retentate and bulk LNOM, and PPNOM, respectively) at the end of dialysis experiments.

\begin{tabular}{lcccccc}
\hline TOC $(\mathrm{mg} \mathrm{C} / \mathrm{L})$ & 3500 Da LMWF & 14000 Da LMWF & 3500 Da retentate & 14000 Da retentate & Bulk & \% LMWF of bulk NOM (\%) \\
\hline PPNOM & 20.57 & 22.44 & 242.70 & 232.10 & 261.80 & 7.8 \\
LNOM & 11.44 & 12.45 & 241.08 & 238.59 & 280.50 & $\mathbf{4 . 1}$ \\
\hline
\end{tabular}

experiments of different molecular weight fractions of PPNOM and LNOM are shown in Figures S1 and S2 in supporting information.

2.4. Chemical Reduction. The samples were chemically reduced by $\mathrm{H}_{2}$ with $\mathrm{Pd} / \mathrm{Al}$ catalysts (palladium-coated aluminum pellets, $0.5 \% \mathrm{Pd}$, Merck) as chemically reduced samples. The reducing capacities of all samples before and after reduction were determined as previously described by Kappler et al. [25] and Yang et al. [26].

2.5. 3DEEM. Fluorescence spectra of all samples before and after reduction were characterized by an F-7000 fluorescence spectrophotometer equipped with both excitation and emission monochromators (Ushio Inc. Japan) with a $1500 \mathrm{~W}$ Xenon arc lamp as the excitation source. The fluorophores were obtained in the form of 3DEEMs via collecting a series of emission spectra over a range of excitation wavelengths, in which fluorescence intensity was presented as a function of excitation wavelength on one axis and emission wavelength on the other. To prevent reduced samples from reoxidizing, the standard $10 \mathrm{~mm}$ four-way quartz cell was prior purged with $\mathrm{N}_{2}$ for 30 mins before analysis. The fluorescence spectra were analyzed as previously described by Yang et al. [26].

\section{Results and Discussion}

3.1. Dialysis Process and TOC Contents. Dialysis experiments were conducted within 5 days to collect different molecular weight fractions (3500 LMWF, 14000 LMWF, 3500 retentate, and 14000 retentate from bulk PPNOM and LNOM), and the results on total organic carbon TOC content among different LMWFs are shown in Table 1. The TOC results of LMWF NOM showed a continuous increase over the dialysis process (not shown), which are in agreement with our previous studies that the continuously released LMWF HS results in an increase in TOC content $[19,26]$. Approximately $4.1-7.8 \%$ LMWF NOMs of bulk LNOM and PPNOM, respectively, were obtained at the end of dialysis, which was obviously higher than only $2 \%$ LMWF HA of total bulk PPHA and LHA shown in our previous study. The results suggested that NOM owned high LMWF NOM, and these LMWF NOMs occupied higher carbon contents than HA. Moreover, we found that, for both PPNOM and LNOM, TOC contents of 14000 LMWF were higher than 3500 LMWF, which suggested that 14000 LMWF NOM had more $\mathrm{C}$ functional groups (i.e., some electron donor and acceptor moieties: phenolic and possibly substituted aromatic carboxylic acid groups, and carbonyl-containing groups. And the number or type of RAFGs of NOM such as quinone/ hydroquinone moieties [14]) that were higher in 14000 LMWF than 3500 LMWF, but not much.

\subsection{Direct Electrochemical Oxidation (DEO) and Reduction} (DER) of Different Molecular Weight Fractions of PPNOM and LNOM. Quantified electron exchange capacities (EECs) including electron accepting capacity (EAC) and electron donating capacity (EDC) of different molecular weight fractions of PPNOM and LNOM were determined by electrochemical methods. The current I of different molecular weight fractions of NOM in DER and DEO experiments is shown in Figure 1 and S1, respectively. No obvious current I was detected in DEO experiments for all molecular fractions in DEO, which suggested that EDC of all LMWF, retentate, and bulk PPNOM and LNOM had no significant contribution to EEC. The I-t curve results of DER experiments showed a similar decreased tendency in current I from $77.46 \mu \mathrm{A}$ to $11.14 \mu \mathrm{A}$ of $3500 \mathrm{LMWF}$ PPNOM/LNOM in $-0.59 \mathrm{~V}$ DER within 50 min reduction until complete final reduction. Moreover, the I-t curve of DER experiment showed a decreased tendency for all molecular fractions of both PPNOM and LNOM with a decreased $E_{\mathrm{h}}$ from $-0.49 \mathrm{~V}$ to $-0.69 \mathrm{~V}$. These results showed EAC of PPNOM and LNOM were related to environment $\mathrm{E}_{\mathrm{h}}$. Electron accepting moieties were distributed and concentrated in low $E_{\mathrm{h}}$.

In addition, we found that the current I of DER experiments in LMWF molecular weight fractions showed a sharp decrease compared to that of bulk NOM with a decrease in $E_{\mathrm{h}}$ range. Bulk NOM showed a relatively higher $\mathrm{Q}_{\mathrm{DER}}$ than LMWF and retentate NOM due to a high TOC in bulk NOM. This result indicated that EAC and EEC of different molecular weight fractions of NOM were highly dependent on its TOC contents.

In order to evaluate total EEC among different molecular weight fractions of NOM, EEC $(\mathrm{EEC}=\mathrm{EAC}+\mathrm{EDC})$ of different molecular weight fractions was normalized to its TOC contents, referring to the number of electron transferred per gram carbon (meq e-/g C), as shown in Figure 2. Since no obvious contribution of EDC of NOM to EEC, the EAC was approximately equal to EEC according to equation (5). The EEC was significant higher in LMWF than in retentate and bulk NOM, suggesting a high electron transfer capacity of LMWF NOM. This is consistent with the previous study reported that the LMWF HA has a great reducing capacity using chemical reduction $\left(\mathrm{H}_{2}\right.$ and $\left.\mathrm{Pd} / \mathrm{Al}\right)$ [26]. Moreover, a small current I responded a low EEC in the low reducing potential of $-0.49 \mathrm{~V}$, while a large current I responded a high EEC in high reducing potentials. The EEC of NOM in reducing potential range of $-0.59 \mathrm{~V}--0.69 \mathrm{~V}$ accounted for up to $90 \%$ EEC in reducing potential range of $-0.49 \mathrm{~V}-0.69 \mathrm{~V}$ (Figure 2). These results indicated that 

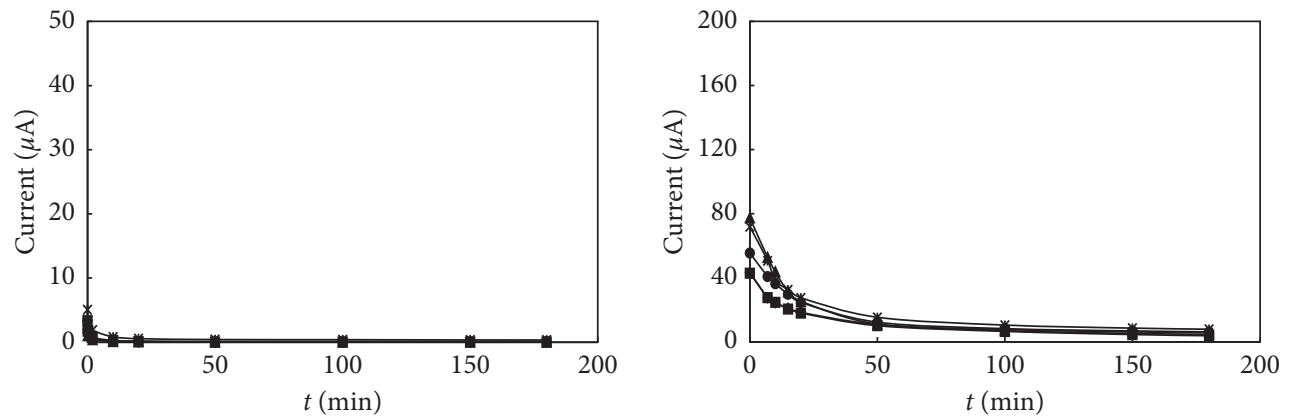

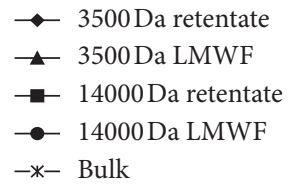

(a)
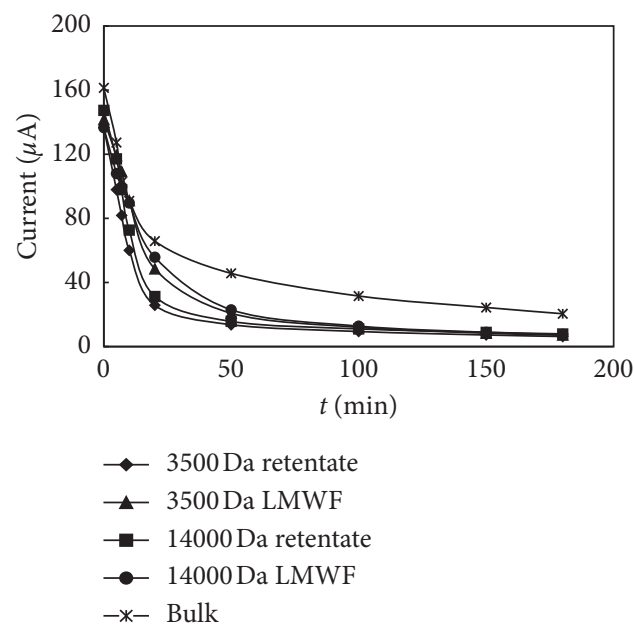

(c)

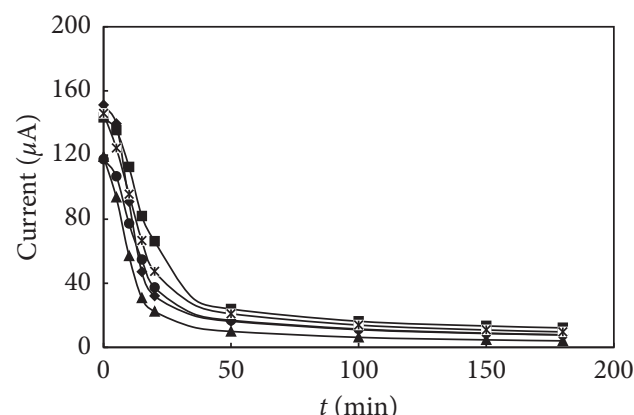

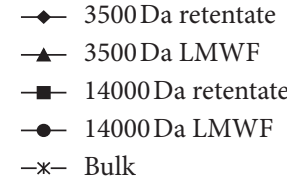

(b)
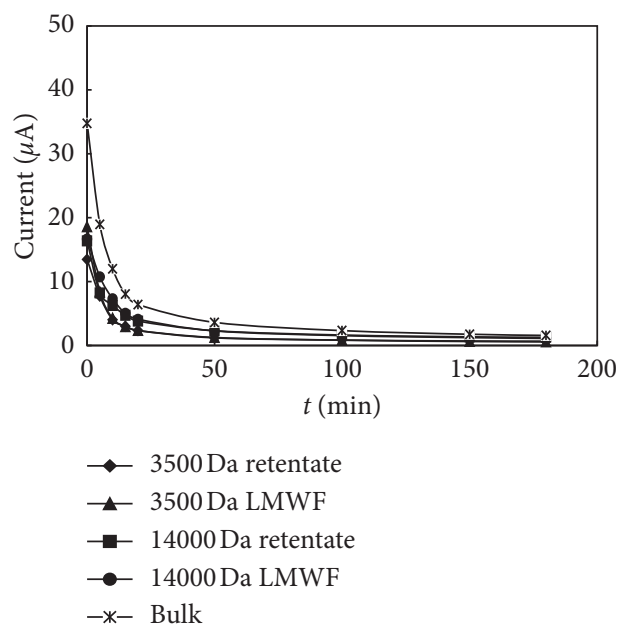

(d)

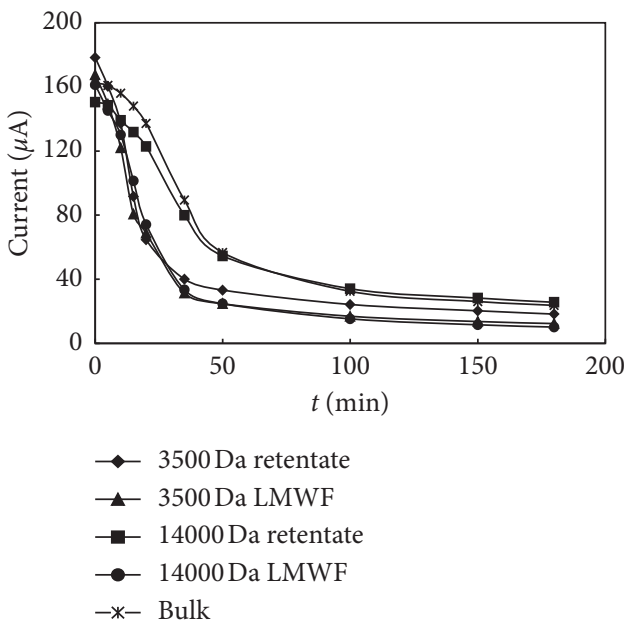

(e)

(f)

FIgURE 1: The I-t curve of different molecular weight fractions of PPNOM and LNOM in DER, which was carried out at $E_{\mathrm{h}}=-0.49 \mathrm{~V}$, $E_{\mathrm{h}}=-0.59 \mathrm{~V}$, and $E_{\mathrm{h}}=-0.69 \mathrm{~V}$ for 3 hours: (a) PPNOM $-0.49 \mathrm{~V}$; (b) PPNOM $-0.59 \mathrm{~V}$; (c) PPNOM 0.69 V; (d) LNOM $-0.49 \mathrm{~V}$; (e) LNOM $-0.59 \mathrm{~V}$; (f) LNOM $-0.69 \mathrm{~V}$.

electron accepting moieties of NOM was distributed mainly at a $E_{\mathrm{h}}$ range of $-0.59 \mathrm{~V}--0.69 \mathrm{~V}$. Compared to PPNOM, LNOM showed a greater EEC; particularly, 3500 LMWF
LNOM had a highest EEC, suggesting 3500 LMWF LNOM had the highest amount of redox-active functional groups. Functional groups in NOM were favorable to accept 
electrons rather than donate electrons; in particular, electron accepting moieties of PPNOM were fully distributed within $E_{\mathrm{h}}$ range of $-0.59 \mathrm{~V}--0.69 \mathrm{~V}$. Reducing capacities of different molecular weight fractions of PPNOM were evaluated by chemical reduction $\left(\mathrm{H}_{2}\right.$ and $\left.\mathrm{Pt} / \mathrm{Al}\right)$, as shown in Figure 3 . Reduced PPNOM showed a higher reducing capacity than that of native PPNOM, indicating that PPNOM possessed more oxidized functional groups, which is in agreement with the results shown by electrochemical analysis. LMWF PPNOM displayed a higher EAC (difference in reducing capacity between reduced state and native state) than retentate and bulk PPNOM (Figure S3), indicating that LMWF had more electron accepting moieties compared to retentate and bulk NOM.

In order to investigate the electron accepting moieties in different NOM samples, we calculated the proportion of EEC in different LMWFs and retentate of PPNOM and LNOM at different $E_{\mathrm{h}}$ of $-0.49 \mathrm{~V}-0.59 \mathrm{~V}$, as shown in Table 2. Calculated EEC of PPNOM accounted for around 3.5-58.4\% of total EEC for both LMWF and retentate. The result suggested that LNOM, compared to PPNOM, has higher amount of electron accepting moieties. In particular, the number of electron accepting moieties in LMWF LNOM obviously higher than in LMWF PPNOM occupied $3.5-5.4 \%$ of LNOM EEC at $E_{\mathrm{h}}$ of $-0.49 \mathrm{~V}$. A decrease in $E_{\mathrm{h}}$ from $-0.49 \mathrm{~V}$ to $-0.59 \mathrm{~V}$ was observed, which resulted in an obvious increase in proportion of LMWF of PPNOM and LNOM from $3.5-5.4 \%$ to $26.4-44.9 \%$ (Table 2). These findings indicated distribution of electron accepting moieties of LMWF NOM is dependent on its $E_{\mathrm{h}}$ range. In this study, we demonstrated that LMWF LNOM with great electron accepting moieties is responsible for a high EEC and EAC.

3.3. Characterization of Redox-Active Functional Fluorophore of LMWF NOM at Different Reducing Potentials by 3DEEM Spectroscopy. In order to clarify responsibility of redoxactive functional moieties/fluorophores of LMWF LNOM to a high electron accepting capacity during the electron transfer process, RAFGs of LMWF LNOM were detected before and after reduction in different $E_{\mathrm{h}}$ ranges of $-0.49--0.59 \mathrm{~V}$ using 3DEEM spectroscopy. Overall, in the native state, 3500 LMWF LNOM had a higher relative fluorescent intensity of humic-like fluorophore with quinonoid $\pi-\pi^{*}$ transition compared to $14000 \mathrm{LMWF}$ (Figure 4 and Table 3). These results suggested that 3500 LMWF occupied more humic-like fluorophores than 14000 LMWF LNOM. Additionally, compared to 14000 LMWF, emission wavelength (Em) of 3500 LMWF showed a shorter Em wavelength position accompanied with a small blue-shifting $(\Delta \mathrm{Em}=5 \mathrm{~nm}$, to a shorter wavelength; Figure 4 and Table 3 ). This result implied that, in the native state, 14000 LMWF had a more complicate structure of redox-active functional fluorophores than 3500 LMWF.

In reduced state with $-0.49 \mathrm{~V}$ potential, compared to native LMWF LNOM, Em of both 3500 LMWF and 14000 LMWF LNOM shifted to a longer Em wavelength $(\Delta \mathrm{Em}=5$

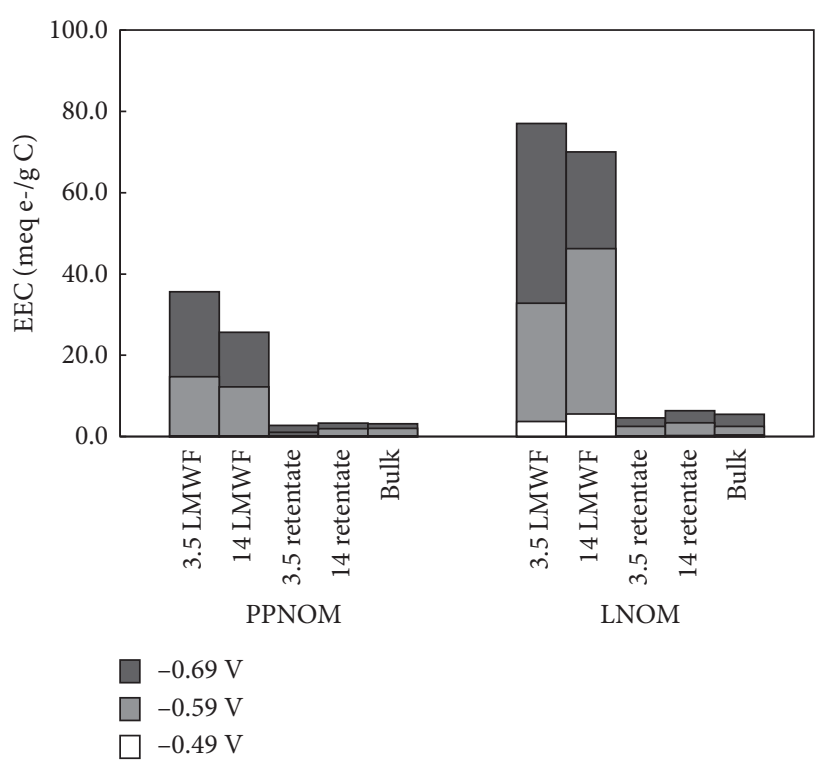

FIgURE 2: The EEC of PPNOM and LNOM.

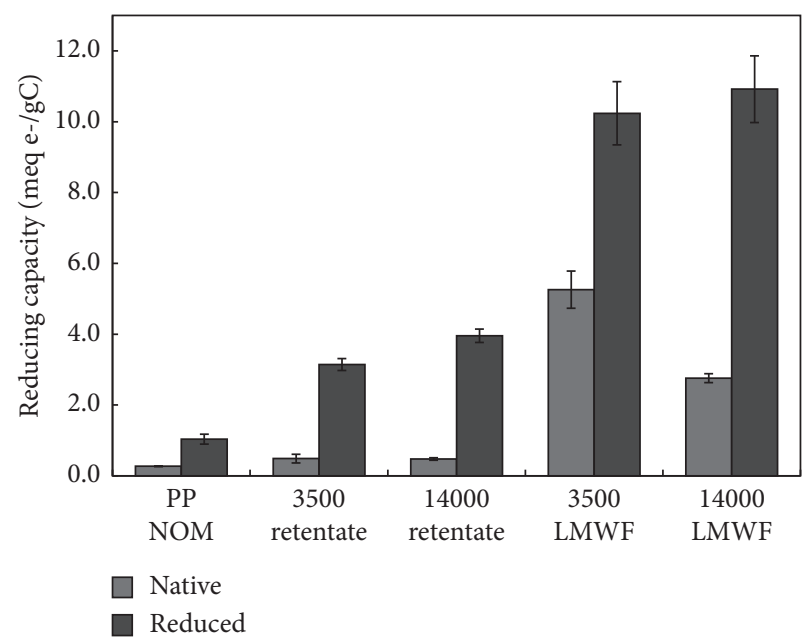

FIgURE 3: The reducing capacity of different molecular weight fractions of PPNOM in their native and reduced states. Each reduced sample was prepared by $\mathrm{H}_{2}$ in the presence of two $\mathrm{Pd}$ catalysts. The reducing capacities were determined by the difference of Fe[III] before and after reacting with ferricyanide. Each data were normalized into meq $\mathrm{e}^{-} / \mathrm{g} \mathrm{C}$, which is equal to $\mathrm{mmol} \mathrm{e}^{-} / \mathrm{g} \mathrm{C}$ in numerical value.

or $10 \mathrm{~nm}$; Figure 4 and Table 3) due to a quinonoid $\pi-\pi^{*}$ transition particularly. These observations indicated that, in reduced state of $-0.49 \mathrm{~V}$, functional groups of LMWF changed to a more complicate structure which most likely to high level condensation in functional groups. Moreover, in reduced state of $-0.59 \mathrm{~V}$, Em still slightly shifted to longer wavelengths $(\Delta \mathrm{Em}=5 \mathrm{~nm})$ for 14000 LMWF and 3500 LMWF compared to native 14000 LMWF and 3500 LMWF and even to LMWF samples in reduced state of $-0.49 \mathrm{~V}$ (Figure 4 and Table 3). These results indicated that a decrease in $E_{\mathrm{h}}$ from $-0.49 \mathrm{~V}$ to $-0.59 \mathrm{~V}$ for LMWF LNOM could lead to an increase in aromatic condensation of redox-active functional groups due to quinonoid $\pi-\pi^{*}$ and benzenoid 
TABLE 2: The proportions of EEC of PPNOM and LNOM.

\begin{tabular}{lcccc}
\hline Reducing potentials & 3500 Da LMWF (\%) & 14000 Da LMWF (\%) & 3500 Da retentate (\%) & 14000 Da retentate (\%) \\
\hline$-0.49 \mathrm{~V}$ & 5.4 & 3.5 & 16.8 & 9.6 \\
$-0.59 \mathrm{~V}$ & 44.9 & 26.4 & 41.9 & 58.4 \\
\hline
\end{tabular}

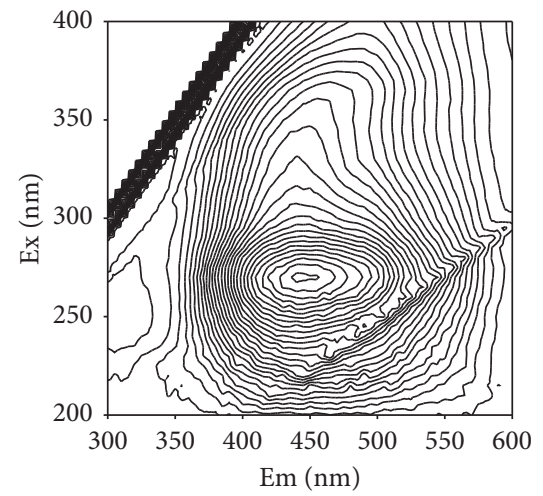

(a)

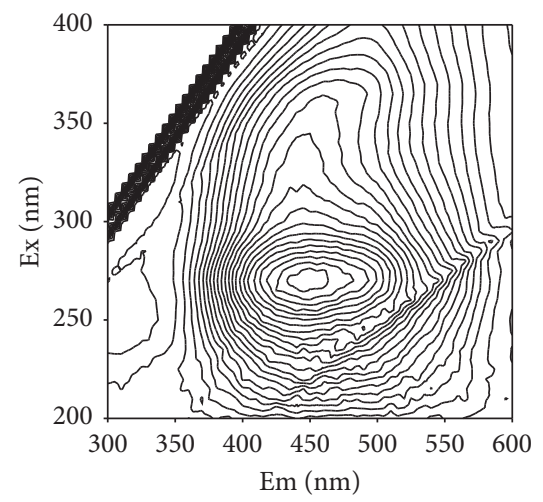

(d)

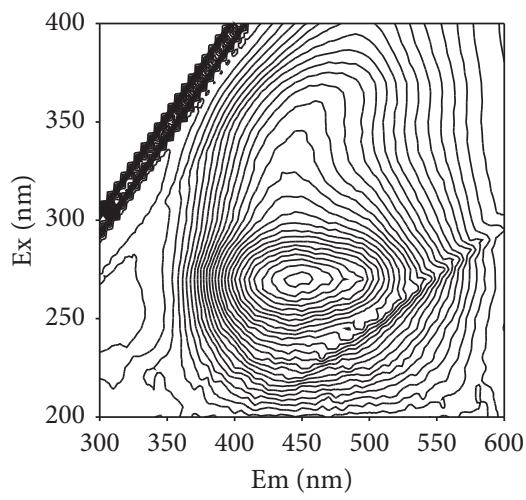

(b)

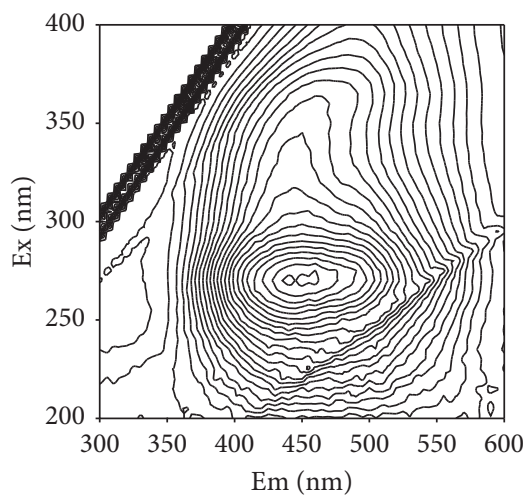

(e)

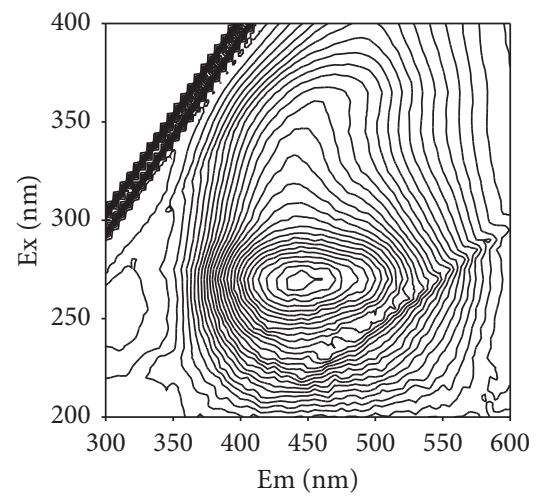

(c)

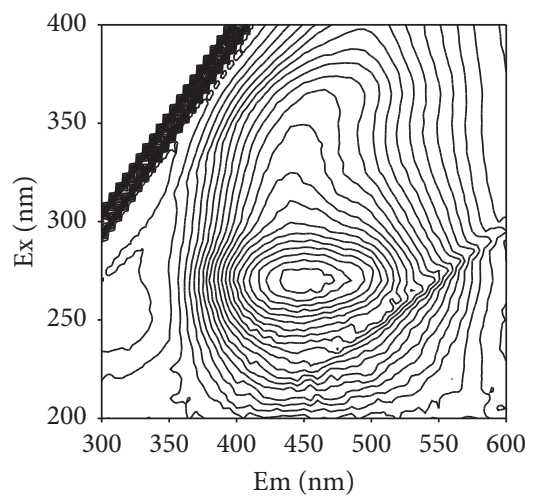

(f)

FIGURE 4: 3DEEM fluorescence spectra of LMWF of LNOM in their native, after $-0.49 \mathrm{~V}$ and $-0.59 \mathrm{~V}$ DER redox state: (a) 3500 LMWF native; (b) $3500 \mathrm{LMWF}-0.49 \mathrm{~V}$; (c) $3500 \mathrm{LMWF}-0.59 \mathrm{~V}$; (d) $14000 \mathrm{LMWF}$ native; (e) $14000 \mathrm{LMWF}-0.49 \mathrm{~V}$; (f) $14000 \mathrm{LMWF}-0.59 \mathrm{~V}$.

TABLE 3: Fluorescence peak positions and relative fluorescence intensities of LMWF of LNOM in different redox states.

\begin{tabular}{|c|c|c|c|c|c|c|c|c|}
\hline \multirow[b]{2}{*}{ Samples } & \multicolumn{4}{|c|}{3500 LMWF } & \multicolumn{4}{|c|}{14000 LMWF } \\
\hline & $\begin{array}{c}\mathrm{Ex} / \mathrm{Em} \\
(\mathrm{nm} / \mathrm{nm})\end{array}$ & $\begin{array}{c}\text { Intensity } \\
\text { (a. u.) }\end{array}$ & Peak type & $\begin{array}{c}\text { Transition } \\
\text { section }\end{array}$ & $\begin{array}{c}\mathrm{Ex} / \mathrm{Em} \\
(\mathrm{nm} / \mathrm{nm})\end{array}$ & $\begin{array}{c}\text { Intensity } \\
\text { (a. u.) }\end{array}$ & Peak type & $\begin{array}{c}\text { Transition } \\
\text { section }\end{array}$ \\
\hline Native & $270 / 440$ & 1.66 & $\begin{array}{l}\text { Humic- } \\
\text { like }\end{array}$ & Quinonoid $\pi-\pi^{*}$ & $275 / 455$ & 1.40 & $\begin{array}{l}\text { Humic- } \\
\text { like }\end{array}$ & Quinonoid $\pi-\pi^{*}$ \\
\hline$-0.49 \mathrm{~V}$ & $270 / 450$ & 1.62 & $\begin{array}{l}\text { Humic- } \\
\text { like }\end{array}$ & Quinonoid $\pi-\pi^{*}$ & $270 / 460$ & 1.38 & $\begin{array}{l}\text { Humic- } \\
\text { like }\end{array}$ & Quinonoid $\pi-\pi^{*}$ \\
\hline$-0.59 \mathrm{~V}$ & 270445 & 1.69 & $\begin{array}{l}\text { Humic- } \\
\text { like }\end{array}$ & Quinonoid $\pi-\pi^{*}$ & $270 / 445$ & 1.30 & $\begin{array}{l}\text { Humic- } \\
\text { like }\end{array}$ & Quinonoid $\pi-\pi^{*}$ \\
\hline
\end{tabular}

$\pi-\pi^{*}$. In addition, after being reduced to $E_{\mathrm{h}}$ range of -0.49 to $-0.59 \mathrm{~V}, 3500 \mathrm{LMWF}$ had a higher relative fluorescent intensity compared to 14000 LMWF LNOM. This finding suggested that 3500 LMWF possessed a relatively low aromatic condensation but high number of quinone-like fluorophore, which was consistent with the result in respect to high EAC in 3500 LMWF LNOM using electrochemical analysis.

\section{Conclusions}

Redox processes impact transformation and transport of redox-active contaminants in environment, which is dependent on $E_{\mathrm{h}}$ and RAFGs of NOM. We evaluated the redox properties of NOM with respect to EECs and RAFGs. We found that the reducing capacity in LMWF PPNOM was approximately 5-6 times higher than that of the bulk NOM, 
while only 7.8\% LMWF PPNOM TOC accounted for bulk PPNOM TOC. An increase in EEC for LMWF PPNOM and LNOM was observed with a reduced $E_{\mathrm{h}}$ range from $-0.49 \mathrm{~V}$ to $-0.69 \mathrm{~V}$. Quinone-like fluorophores in LMWF LNOM were distributed and concentrated in $E_{\mathrm{h}}$ range of -0.49 $\mathrm{V}--0.69 \mathrm{~V}$. These quinone-like fluorophores with a redshifting in emission wavelength were observed with a reduced $E_{\mathrm{h}}$ range from $-0.49 \mathrm{~V}$ to $-0.59 \mathrm{~V}$. The findings can provide a better understanding of relationship between RAFGs $E_{\mathrm{h}}$ in LMWF of NOM and thus can help to predict fates of redox-active contaminants in LMWF NOM-containing groundwater environment.

\section{Data Availability}

The experimental data used to support the findings of this study are included in the article. And more detailed data are available from the corresponding author upon request.

\section{Conflicts of Interest}

The authors declare that there are no conflicts of interest regarding the publication of this paper.

\section{Acknowledgments}

This research was supported by the Major Science and Technology Program for Water Pollution Control and Treatment of China (2018ZX07208001) and the National Natural Science Foundation of China (21677012) to J.J.

\section{Supplementary Materials}

Supplementary Figure S1: the EDC of different molecular weight fractions of PPNOM and LNOM in DEO experiments. The applied potential is $+0.61 \mathrm{~V}$. Supplementary Figure S2: the I-t curve of different molecular weight fractions of PPNOM (a) and LNOM (b) in DEO experiments, which was carried out at $+0.61 \mathrm{~V}$ for 3 hours. Supplementary Figure S3: the EAC of different molecular weight fractions of PPNOM calculated by the chemical reductions and proceeding. (Supplementary Materials)

\section{References}

[1] J. D. Coates, R. Chakraborty, S. M. O’Connor, C. Schmidt, and J. Thieme, "The geochemical effects of microbial humic substances reduction," Acta hydrochimica et hydrobiologica, vol. 28 , no. 7, pp. 420-427, 2001.

[2] Z. Struyk and G. Sposito, "Redox properties of standard humic acids," Geoderma, vol. 102, no. 3-4, pp. 329-346, 2001.

[3] A. Kappler and S. B. Haderlein, "Natural organic matter as reductant for chlorinated aliphatic pollutants," Environmental Science \& Technology, vol. 37, no. 12, pp. 2714-2719, 2004.

[4] D. R. Lovley, J. D. Coates, E. L. Blunt-Harris, E. J. P. Phillips, and J. C. Woodward, "Humic substances as electron acceptors for microbial respiration," Nature, vol. 382, no. 6590, pp. 445-448, 1996.

[5] S. Mitsunobu, T. Harada, and Y. Takahashi, "Comparison of antimony behavior with arsenic under various soil redox conditions," Environmental Science \& Technology, vol. 25, no. 1, pp. 98-99, 2006.

[6] J. Singh, S. D. Comfort, and P. J. Shea, "Iron-mediated remediation of RDX-contaminated water and soil under controlled eh/pH," Environmental Science \& Technology, vol. 33, no. 9, pp. 1488-1494, 1999.

[7] J. J. Alberts, J. E. Schindler, R. W. Miller, and D. E. Nutter, "Elemental mercury evolution mediated by humic acid," Science, vol. 184, no. 4139, pp. 895-897, 1974.

[8] J. Chen, "The roles of natural organic matter in chemical and microbial reduction of ferric iron," Science of the Total Environment, vol. 307, no. 1-3, pp. 167-178, 2003.

[9] J. Jiang, I. Bauer, A. Paul, and A. Kappler, "Arsenic redox changes by microbially and chemically formed semiquinone radicals and hydroquinones in a humic substance model quinone," Environmental Science \& Technology, vol. 43, no. 10, pp. 3639-3645, 2009.

[10] M. Aeschbacher, M. Sander, and R. P. Schwarzenbach, "Novel electrochemical approach to assess the redox properties of humic substances," Environmental Science \& Technology, vol. 44, no. 1, pp. 87-93, 2010.

[11] B. Gu, J. Schmitt, Z. Chen, L. Liang, and J. F. McCarthy, "Adsorption and desorption of natural organic matter on iron oxide: mechanisms and models," Environmental Science \& Technology, vol. 28, no. 1, pp. 38-46, 1994.

[12] C. Jie, "Fluorescence spectroscopic studies of natural organic matter fractions," Chemosphere, vol. 50, no. 5, pp. 0-647, 2003.

[13] E. Z. Fratczak, "Spectroscopic characterization of the structural properties of quinoxalinophenanthrophenazine thin films," Journal of Materials Chemistry C, vol. 6, 2018.

[14] D. J. Dryer, G. V. Korshin, and M. Fabbricino, "In situ examination of the protonation behavior of fulvic acids using differential absorbance spectroscopy," Environmental Science \& Technology, vol. 42, no. 17, pp. 6644-6649, 2008.

[15] S. M. Phillips, A. D. Bellcross, and G. D. Smith, "Light absorption by Brown carbon in the southeastern United States is pH-dependent," Environmental Science \& Technology, vol. 51, no. 12, pp. 6782-6790, 2017.

[16] E. S. Boyle, N. Guerriero, A. Thiallet, R. D. Vecchio, and N. V. Blough, "Optical properties of humic substances and CDOM: relation to structure," Environmental Science \& Technology, vol. 43, no. 7, pp. 2262-2268, 2009.

[17] R. Del Vecchio and N. V. Blough, "On the origin of the optical properties of humic substances," Environmental Science \& Technology, vol. 38, no. 14, pp. 3885-3891, 2004.

[18] C. M. Sharpless and N. V. Blough, "The importance of chargetransfer interactions in determining chromophoric dissolved organic matter (CDOM) optical and photochemical properties," Environmental Science Process Impacts, vol. 16, no. 4, 2014.

[19] J. Cao and J. Jiang, "Reducing capacities in continuously released low molecular weight fractions from bulk humic acids," Journal of Environmental Management, vol. 244, pp. 172-179, 2019.

[20] G. R. Aiken, "Humic substances in soil, sediment, and water: geochemistry, isolation, and characterization," Journal of Environmental Management, vol. 142, no. 5, 1985.

[21] G. C. Curtis and M. Reinhard, "Reductive dehalogenation of hexachloroethane, carbon tetrachloride, and bromoform by anthrahydraquinone disulfonate and humic acid," Environmental Science \& Technology, vol. 28, pp. 2360-2365, 1994.

[22] F. J. Stevenson, Humus Chemistry: Genesis, Composition, Reactions, Springer, Berlin, Germany, 2nd edition, 1982. 
[23] B. Gu and J. Chen, "Enhanced microbial reduction of $\mathrm{Cr}(\mathrm{VI})$ and U(VI) by different natural organic matter fractions," Geochimica Et Cosmochimica Acta, vol. 67, no. 19, pp. 3575-3582, 2003.

[24] F. Maurer, I. Christl, B. Fulda, A. Voegelin, and R. Kretzschmar, "Copper redox transformation and complexation by reduced and oxidized soil humic acid. 2. Potentiometric titrations and dialysis cell experiments," Environmental Science \& Technology, vol. 47, no. 19, pp. 10912-10921, 2013.

[25] A. Kappler, M. Benz, B. Schink, and A. Brune, "Electron shuttling via humic acids in microbial iron(III) reduction in a freshwater sediment," Fems Microbiology Ecology, vol. 47, no. 1, pp. 85-92, 2004.

[26] Z. Yang, A. Kappler, and J. Jiang, "Reducing capacities and distribution of redox-active functional groups in low molecular weight fractions of humic acids," Environmental Science \& Technology, vol. 10, 2016.

[27] M. Sander, T. B. Hofstetter, and C. A. Gorski, "Electrochemical analyses of redox-active iron minerals: a review of nonmediated and mediated approaches," Environmental Science \& Technology, vol. 49, no. 10, pp. 5862-5878, 2015.

[28] M. Bauer, T. Heitmann, D. L. Macalady, and C. Blodau, "Electron transfer capacities and reaction kinetics of peat dissolved organic matter," Environmental Science \& Technology, vol. 41, no. 1, pp. 139-145, 2007.

[29] Y. Wang, "Nanogeochemistry: nanostructures, emergent properties and their control on geochemical reactions and mass transfers," Chemical Geology, vol. 378-379, pp. 1-23, 2014.

[30] A. Piepenbrock, C. Schröder, and A. Kappler, "Electron transfer from humic substances to biogenic and abiogenic $\mathrm{Fe}(\mathrm{III})$ oxyhydroxide minerals," Environmental Science \& Technology, vol. 48, no. 3, pp. 1656-1664, 2014. 